\title{
In-situ Observation of Radiation Damage in Nano-structured Amorphous SiOC/Crystalline Fe Composite
}

Qing $\mathrm{Su}^{1 *}$, Bai Cui ${ }^{2}$, Marquis A. Kirk ${ }^{3}$ and Michael Nastasi ${ }^{1,2,4}$

${ }^{1}$ Nebraska Center for Energy Sciences Research, University of Nebraska-Lincoln, Lincoln, NE 68583-0857, USA

${ }^{2}$ Department of Mechanical and Materials Engineering,University of Nebraska-Lincoln, Lincoln, NE 68583-0857, USA

${ }^{3}$ Nuclear Engineering Division, Argonne National Laboratory, Argonne, IL 60439, USA

${ }^{4}$ Nebraska Center for Materials and Nanoscience, University of Nebraska-Lincoln, Lincoln, NE 68588-0298, USA

\begin{abstract}
The radiation tolerance property of amorphous silicon oxycarbide (SiOC)and crystalline Fe nanocomposites wereexamined by in-situ transmission electron microscopeat 50 Kelvin (K), room temperature and573 K.Resultsshowed that intermixing between Fe and SiOCwas most severe for irradiationat $50 \mathrm{~K}$. However, for irradiations at $573 \mathrm{~K}$, a demixing process was observed. The results indicated thermodynamic stability and radiation tolerance of $\mathrm{Fe} / \mathrm{SiOC}$ nanocomposite at elevated temperature. Compared with thin $\mathrm{Fe} / \mathrm{SiOC}$ multilayers, thick $\mathrm{Fe} / \mathrm{SiOC}$ multilayer exhibited better irradiation stability. Discussion cover two possible reasons for these observations including the role composite interface energy and collision cascade size.
\end{abstract}

Keyword: Radiation tolerant materials, amorphous SiOC, nanocrystalline Fe, interface.

*Corresponding author. Tel.: +1 (402) 472-4242

Email address:qsu3@unl.edu 


\section{Introduction}

Next-generation nuclear energy technology requiresthe development of radiation tolerant materials which experienceminor structural changes and minimum thermal/mechanical degradation under harsh environments toensure longer and safer life cycles.[1, 2] One of the emerging approaches of removing radiation damage and suppressing radiation induced dimensional and property changes is to develop materials with engineered grain boundaries and interfaces that serve as defect sinks.[3] For example, grain boundaries of nanocrystalline metals have been demonstrated to assist defect annihilation and enhance radiation resistance.[4, 5]Interfaces between nanoscale oxide particles and the metal matrix have been proven to enhance swelling resistance and creep resistancein oxide dispersion strengthened (ODS) steels systems.[6, 7]In addition, several incoherent interfaces including $\mathrm{Cu} / \mathrm{Nb}$,[8] $\mathrm{Cu} / \mathrm{V}$,[9] $\mathrm{Fe} / \mathrm{W}[10]$ interfaces have beenshownas strong defect sinks to promote vacancies and interstitials recombination. Rather than preventing microstructure changes in polycrystalline aggregates, a new kind of irradiation tolerant material, amorphous silicon oxycarbide (SiOC), has been developed recently whoseamorphous microstructureremains unchanged after irradiation. Studieshave shown that SiOC alloys remain amorphous atboth room temperature and $600{ }^{\circ} \mathrm{C}$ irradiation with damage levels up to 20 displacements per atom (dpa).[11, 12] To possess good mechanical properties, be capable of operation at temperatures greater than $500^{\circ} \mathrm{C}$, and have extreme radiation tolerance, an amorphous SiOC/crystalline Fe composite has been developed. $\alpha-\mathrm{Fe}$, in the composite, was chosen to serve as a model material for steel.[13]From a preliminary study, the $\alpha$-Fe/amorphous SiOC composite showed radiation stability after He irradiation to $~ 1.3$ dpa at room temperatureand the crystalline/amorphous interface was shown to be effective at annihilating point defects and enhancing radiation tolerant properties.[14]

Compared with ex-situ situ transmission electron microscope(TEM) experiments, which only observes the initial and final stage of irradiated specimen, in-situ irradiations inside a TEM provides real-time observation of microstructural evolution in irradiated composite materials.Therefore, in-situ irradiations offer a unique way to examine the dynamics of defectdefect and defect-interface interactions. Many phenomena have been observed via TEM in-situ irradiation studies, such as irradiation-induced grain growth in $\mathrm{Zr}$ and $\mathrm{Fe},[15]$ defect removal by twin boundaries,[16] and defect migration kinetics in nanoporous metals.[17] 
In extension to our previous work on light ion $(\mathrm{He})$ irradiation which produces dilute and small collision cascades, this in-situ study examined the heavy ion $(\mathrm{Kr})$ irradiation response of $\mathrm{Fe} / \mathrm{SiOC}$ nanocomposites at $50 \mathrm{~K}, \mathrm{RT}$ and $573 \mathrm{~K}$.Heavy ion $(\mathrm{Kr})$ irradiation results in dense and large collision cascades which is vital to the examination of our nanocomposite radiation stability. Besides collision cascade size and density the, irradiation temperature is another key factor affectingstability through the kinetics of defect-defect and defect-interface interactions. For example, irradiation at $50 \mathrm{~K}$ results in low defect mobility and a high density of retained Frenkel pairs, while irradiation at elevated temperature leads to high defect mobility and formation of vacancy and interstitial clusters.[18]The aim of this work is to investigate irradiation response of $\mathrm{Fe} / \mathrm{SiOC}$ nanocomposite with crystalline/amorphous interfaces at these three temperature points.

\section{Experimental}

In this work, magnetron sputteringwas used to fabricate nano-structured $\mathrm{Fe} / \mathrm{SiOC}$ multilayer films with controlled individual layer thicknesses. Prior to depositions, the base pressure was $9.8 \times 10^{-6} \mathrm{~Pa}$ or lower.The Ar partial pressure used for filmdeposition was $\sim 0.65$ Pa.DC magnetron sputtering was used to prepare nanocrystalline $\alpha$-Fe layers whileradio frequency $(\mathrm{RF})$ co-sputtering was used to synthesize amorphous $\mathrm{SiOC}$ layers from $\mathrm{SiO}_{2}$ and $\mathrm{SiC}$ targets at room temperature. The total thickness of all films was $420 \mathrm{~nm}$ and the individual layer thicknesses wascontrolled by deposition time. In thick Fe/SiOC multilayer films, Fe and SiOC layers were 60, $80 \mathrm{~nm}$ in thickness, respectively. The individual layer thickness for thin $\mathrm{Fe} / \mathrm{SiOC}$ multilayer films was $14 \mathrm{~nm}$. The detailed microstructure characterization of as-deposited $\mathrm{Fe} / \mathrm{SiOC}$ multilayers can be found in reference.[19]

All cross-sectional transmission electron microscopy (TEM) specimens were prepared by grinding, polishing and ion milling. During TEM sample preparation, low energy (3.5 keV) and low angle $\left(5^{\circ}\right)$ were selected to reduce the ion milling-induced damage.The cross-sectional microstructure of $\mathrm{Fe} / \mathrm{SiOC}$ multilayers before and after irradiation was investigated by an FEI Tecnai G2 F20 microscopeoperated at $200 \mathrm{keV}$. A set ofFe/SiOC multilayer specimens were insitu irradiated with $1 \mathrm{MeV} \mathrm{Kr}$ ions at the IVEM-TANDEM facility at Argonne National Laboratory, where an ion accelerator is attached to a HITACHI H-9000NAR microscopewith an operation voltage of $200 \mathrm{keV}$. Irradiation temperatures were $50 \mathrm{~K}$, RT and $573 \mathrm{~K}$. The ion beam 
size was $1.5 \mathrm{~mm}$ (without rastering) which was able to cover the whole TEM specimen. Depthdependent damage and defect concentration profiles were calculated by the Stopping and Range of Ions in Matter (SRIM)-2008using the ion distribution and quick calculation of damage option in the SRIM software.[20]

\section{Results and discussion}

$1 \mathrm{MeV} \mathrm{Kr}$ ions were selected for the irradiationof Fe/SiOC multilayer films. The SRIM calculated projected range for $1 \mathrm{MeV} \mathrm{Kr}$ in $\mathrm{Fe}$ and $\mathrm{SiOC}$ is $241.3 \mathrm{~nm}$ and $700.2 \mathrm{~nm}$, respectively.Because bothranges far exceededthe thickness of theTEM specimens $(\sim 100 \mathrm{~nm})$, the majority of $\mathrm{Kr}$ ionspenetrate through the thin Fe/SiOC specimen.Fig. 1a presents the experimental set-up for irradiation of TEM specimens. The accelerated $\mathrm{Kr}$ ions bombard the TEM specimen with an incident angle of $\sim 15^{\circ}$. Since the $\mathrm{Kr}^{++}$ion beam direction is almost parallel with the $\mathrm{Fe} / \mathrm{SiOC}$ interface, damage simulationswere carried out for the $\mathrm{Fe}$ and $\mathrm{SiOC}$ layers separately. Fig. 1b and 1c show the SRIM dpa profiles in the Fe and SiOC films respectively with a fluence of $4 \times 10^{14}$ ions $/ \mathrm{cm}^{2}$. These data show that the $\mathrm{Kr}^{++}$irradiation damage with a dose of $4 \times 10^{14}$ ions $/ \mathrm{cm}^{2}$ is $\sim 1.1 \mathrm{dpa}$ in the Fe layers and $\sim 0.42 \mathrm{dpa}$ in the SiOC layers.

Fig. 2a shows typical cross-sectional bright-field TEM micrographs of thin Fe/SiOC multilayer films before $\mathrm{Kr}$ irradiationwhere there are alternating $\mathrm{Fe}$ and SiOC nanolayers with clear interfaces. The as-deposited Fe layers exhibit a typical columnar growth with average grain size of $\sim 20 \mathrm{~nm}$ while all SiOC layers show uniform contrast. The corresponding selective area diffraction (SAD) patterns shown as insets of Fig. 2a exhibit a diffuse halo around the central beam and ring diffraction patterns with similar interval spacing, suggesting the amorphous nature of the SiOC layers and body-centered cubic (BCC) structure of Fe, respectively. To further examine the radiation stability in Fe/SiOC nanocomposite as a function of temperature, in-situ irradiation were performed at $50 \mathrm{~K}$, RT and $573 \mathrm{~K}$. Fig. $2 \mathrm{~b}$ presents the microstructure of thin $\mathrm{Fe} / \mathrm{SiOC}$ multilayer after irradiation at $50 \mathrm{~K}$ with dose of $4 \times 10^{14}$ ions $/ \mathrm{cm}^{2}$. The nanolayer structure has been completely destroyed and severe irradiation induced intermixing between Fe layers and $\mathrm{SiOC}$ layers is observed.However, the corresponding SAD pattern shows that this ion mixed Fe/SiOC film is still composed of nanocrystalline $\alpha$-Feand an amorphous phase.In comparison, the thin $\mathrm{Fe} / \mathrm{SiOC}$ sample irradiated at room temperature exhibits less intermixing. Several un-mixed areas with bright contrast are observed in Fig. 2c. Also, the nanocrystalline $\alpha$ - 
$\mathrm{Fe}$ and amorphous phases coexist in Fe/SiOC film after RT irradiation, which is confirmed by the corresponding SAD pattern (shown as inset of Fig. 2c). In contrast to the intermixing observed at50 K and RT, no Fe and SiOC intermixing is observed in the sample irradiated at 573 Kwith a doubled dose of $8 \times 10^{14}$ ions $/ \mathrm{cm}^{2}$ (Fig. 2d). The results suggest that a demixing process takes place within the thin Fe/SiOC multilayer during $573 \mathrm{~K}$ irradiation to maintain phase separation and a layered structure.

Fig. 3a presents the cross-sectional bright-field TEM micrograph of as-deposited thick $\mathrm{Fe} / \mathrm{SiOC}$ multilayer films. It exhibits similar Fe grain size and same crystal structure with that of thin Fe/SiOC multilayer films shown in Fig. 2a. Compared with the thin multilayer films, the thick Fe/SiOC multilayers exhibits better radiation stabilityafter irradiation at $50 \mathrm{~K}$ with dose of $4 \times 10^{14}$ ions $/ \mathrm{cm}^{2}$, (Fig. 2b). The Fe/SiOC interfaces are all clearly observed after the $50 \mathrm{~K}$ irradiations, indicating no irradiation-induced mixing or secondary phase formation between the Fe layers and the amorphous SiOC layers. As the dose increases to $1 \times 10^{15}$ ions $/ \mathrm{cm}^{2}$, an intermixed layer with thickness of $\sim 10 \mathrm{~nm}$ is observed between Fe layer and SiOC layer as seen in Fig. 3c.To further examine the composition profile of the multilayers irradiated with $1 \times 10^{15}$ ions $/ \mathrm{cm}^{2}$, scanning transmission electron microscopy (STEM) was conducted under a high-angle annular dark field (HAADF) condition.The STEM images of Fig. 3dshow thata light contrast layer is observed between the bright contrast Fe layer and dark contrast SiOC layer. Element mapping (not shown here) reveals the formation of a $\mathrm{Fe}_{\mathrm{x}} \mathrm{Si}_{\mathrm{y}} \mathrm{O}_{\mathrm{z}}$ interlayer.Cross-sectional TEM images of thick Fe/SiOC multilayer after RTand573 Kirradiation with dose of $1 \times 10^{15}$ ions $/ \mathrm{cm}^{2}$ are shown as Fig. 3e and 3f, respectively. Thick Fe/SiOC multilayer films exhibit clear interfaces after RT and $573 \mathrm{~K}$ irradiation without the formation of $\mathrm{Fe}_{\mathrm{x}} \mathrm{Si}_{\mathrm{y}} \mathrm{O}_{\mathrm{z}}$ layer.The insetsof Fig. $3 \mathrm{e}$ and $3 \mathrm{f}$ are the corresponding $\mathrm{SAD}$ patternsshowingBCC $\mathrm{Fe}$ and amorphous SiOC diffraction patterns.

Two most important features observed during in-situ Kr irradiation at $50 \mathrm{~K}$, RT and 573 $\mathrm{K}$ are as follows:

(i) $\mathrm{Fe} / \mathrm{SiOC}$ layered structures aremore radiation tolerant at elevated temperature $(573 \mathrm{~K})$ than that at low temperature $(50 \mathrm{~K})$.

(ii) $\mathrm{Fe} / \mathrm{SiOC}$ multilayer films with larger length scale are more radiation stable than films with smaller length scale. 
Perhaps the most significant feature of the $\mathrm{Fe} / \mathrm{SiOC}$ multilayers after $\mathrm{Kr}$ irradiation after different temperatures is the higher radiation stability at elevated temperatures. The results suggest that the breakdown mechanism for thin $\mathrm{Fe} / \mathrm{SiOC}$ multilayer films is ballistic mixing. When $\mathrm{Kr}$ ions interact with $\mathrm{Fe} / \mathrm{SiOC}$ multilayers, the interaction results innumerous collision cascades and subcascades which force $\mathrm{Fe}$ and $\mathrm{SiOC}$ atoms to intermix with each other. At low temperature $(50 \mathrm{~K})$, there is negligible thermal energy for mixed atoms to diffuse. Therefore, the movement of these atoms is restrictedwithin the cascade (estimated $0.7 \mathrm{~nm}$ diffusion length at 1 dpa $\mathrm{Kr}$ irradiation)[21] and leads tointermixing between $\mathrm{Fe}$ and $\mathrm{SiOC}$ atoms. As the dose increases, the collision cascades overlap, leading to the observed layer breakdown. At elevated temperature $(573 \mathrm{~K})$, thermal energy enables atomic movement after cascades- intermixing. Both thin and thick $\mathrm{Fe} / \mathrm{SiOC}$ multilayers after $\mathrm{Kr}$ irradiation at $573 \mathrm{~K}$ clearly show stable layered structures, indicating that intermixed $\mathrm{Fe}$ and $\mathrm{SiOC}$ atoms de-mix and suggesting that there is a positive heat of mixing between those two materials. As long as kinetics permit, Fe layers and SiOC layers prefer to stay with their original form. Moreover, irradiation induced point defects are more mobile at elevated temperature, which allow them to migrate to defect sinks ( $\mathrm{Fe} / \mathrm{SiOC}$ crystalline/amorphous interface or $\mathrm{Fe}$ grain boundaries in this system) to recombine, enhancingthe stability of $\mathrm{Fe} / \mathrm{SiOC}$ nanocomposite system.

$\mathrm{Fe}$ and SiOC nanocomposites appear to bethermodynamically stable and tend to a layered structure during irradiation at elevated temperature. However, at this point it is unclear why intermixing and layer breakdown is observed in the thin Fe/SiOC multilayers. One possibility is that the greater number of interfaces adds additionalpositive enthalpy to the system, as suggested by Liu et al.[22, 23] Liu et al. have shown that interfaces can assist ion-beam mixing in several immiscible metallic systems even with a large positive heat of mixing. For low temperature irradiation where radiation induced point defects cannot migrate, the Fe/SiOC nanocomposite systems with a greater interfacial area per unit volume are more vulnerable to mixing. This hypothesis is supported by the observations that show that there is less intermixing for thick $\mathrm{Fe} / \mathrm{SiOC}$ multilayer films compared to that of thin multilayer films at the same doses and temperatures.Another possibility is that the layered structure is damaged by one collision cascade.To estimate the cascade size of $1 \mathrm{MeV}$ Kr irradiation, a SRIM simulation was performed to examine the 3-D vacancy distribution inside the Fe layers. Fig. 4a presents the 3D-vacancy depth profile where the lateral and longitudinal concentrations increase with projectile depth. An 
estimate of the cascade width can be made by determining the lateral straggling in the vacancy concentration. The lateral vacancy distribution at $50 \mathrm{~nm}$, fitted with aGaussian distribution, is shownFig $2 \mathrm{~b}$, which renders a variance of $\sim 3.2 \mathrm{~nm}$. Relating the variance to a cascade width requires multiplying the Monte Carlo value obtained from TRIM by a correction factor of 0.77. $[24,25]$ This gives the approximate radius of a $\mathrm{Kr}$ cascade in the TEM specimen of $\sim 2.5 \mathrm{~nm}$. Thus, the collision cascade diameter is $\sim 5 \mathrm{~nm}$ which is less than the thickness of SiOC layer (14 $\mathrm{nm})$. Because the collision cascade size does not exceed the thickness of individual layer, it is expected that only overlapped collision cascade can result in layer breakdown in this case. However, once the average size of collision cascade is bigger than the layer length scale, one cascade may damage the layered structure within this cascade regime during low temperature irradiation.

\section{Conclusions}

We examined the temperature dependent $\mathrm{Kr}$ radiation stability of the $\mathrm{Fe} / \mathrm{SiOC}$ composite system. $\mathrm{Fe} / \mathrm{SiOC}$ nanocomposite systems exhibit better $\mathrm{Kr}$ radiation stability at elevated temperature $(573 \mathrm{~K})$ than that at low temperature $(50 \mathrm{~K})$. The results suggest that the layered structure is damaged by ballistic ion mixing. Also, $\mathrm{Fe}$ and SiOC tend to de-mix during irradiation at elevated temperatures and $\mathrm{Fe} / \mathrm{SiOC}$ crystalline/amorphous interface acts as efficient defect sinks. Compared with thin $\mathrm{Fe} / \mathrm{SiOC}$ multilayers, thick $\mathrm{Fe} / \mathrm{SiOC}$ multilayer films possess better radiation tolerance properties for alldoses and temperatures studied.This suggests that the greater number of interfaces adds additional mixing enthalpy to the system. By estimation of the radius of the $\mathrm{Kr}$ collision cascade, layer breakdown appears to require overlapping collision cascades.

\section{Acknowledgements}

We acknowledge financial support from the DoE Office of Nuclear Energy, Nuclear Energy Enabling Technologies, award DE-NE0000533. The work was carried out in part in the Central Facilities of the Nebraska Center for Materials and Nanoscience, which is supported by the Nebraska Research Initiative. We also thank Peter M. Baldo,Meimei Li and Edward A. Ryan at Argonne National Laboratory for their help and discussion during in situ irradiation experiments. The IVEM facility at Argonne National Laboratory is supported by DOE-NE. 


\section{References}

[1] G.R. Odette, M.J. Alinger, B.D. Wirth, Annu Rev Mater Res, 38 (2008) 471-503.

[2] G.S. Was, J Nucl Mater, 367-370, Part A (2007) 11-20.

[3] I.J. Beyerlein, M.J. Demkowicz, A. Misra, B.P. Uberuaga, Progress in Materials Science, 74 (2015) 125-210.

[4] D. Chen, J. Wang, T.Y. Chen, L. Shao, Sci Rep-Uk, 3 (2013).

[5] X.M. Bai, A.F. Voter, R.G. Hoagland, M. Nastasi, B.P. Uberuaga, Science, 327 (2010) 16311634.

[6] G.R. Odette, D.T. Hoelzer, Jom-Us, 62 (2010) 84-92.

[7] C.P.C. Wong, R.E. Nygren, C.B. Baxi, P. Fogarty, N. Ghoniem, H. Khater, K. McCarthy, B. Merrill, B. Nelson, E.E. Reis, S. Sharafat, R. Schleicher, D.K. Sze, M. Ulrickson, S. Willms, M. Youssef, S. Zinkle, A. Team, Fusion Engineering and Design, 49-50 (2000) 709-717.

[8] A. Misra, M.J. Demkowicz, X. Zhang, R.G. Hoagland, Jom-Us, 59 (2007) 62-65.

[9] E.G. Fu, A. Misra, H. Wang, L. Shao, X. Zhang, J Nucl Mater, 407 (2010) 178-188.

[10] N. Li, E.G. Fu, H. Wang, J.J. Carter, L. Shao, S.A. Maloy, A. Misra, X. Zhang, J Nucl Mater, 389 (2009) 233-238.

[11] M. Nastasi, Q. Su, L. Price, J.A. Colón Santana, T. Chen, R. Balerio, L. Shao, J Nucl Mater, 461 (2015) 200-205.

[12] J.A. Colón Santana, E.E. Mora, L. Price, R. Balerio, L. Shao, M. Nastasi, Nuclear Instruments and Methods in Physics Research Section B: Beam Interactions with Materials and Atoms, 350 (2015) 6-13.

[13] D. Brimbal, E. Meslin, J. Henry, B. Decamps, A. Barbu, Acta Mater, 61 (2013) 4757-4764.

[14] Q. Su, L. Price, J.A. Colon Santana, L. Shao, M. Nastasi, Materials Letters, 155 (2015) 138141.

[15] D. Kaoumi, A.T. Motta, R.C. Birtcher, J Appl Phys, 104 (2008).

[16] K.Y. Yu, D. Bufford, C. Sun, Y. Liu, H. Wang, M.A. Kirk, M. Li, X. Zhang, Nat Commun, 4 (2013).

[17] E.M. Bringa, J.D. Monk, A. Caro, A. Misra, L. Zepeda-Ruiz, M. Duchaineau, F. Abraham, M. Nastasi, S.T. Picraux, Y.Q. Wang, D. Farkas, Nano Lett, 12 (2012) 3351-3355.

[18] C.C. Fu, J. Dalla Torre, F. Willaime, J.L. Bocquet, A. Barbu, Nat Mater, 4 (2005) 68-74. 
[19] Q. Su, L. Price, J.A. Colon Santana, L. Shao, M. Nastasi, Materials Letters, 155 (2015) 138141.

[20] J.B.B. J.F. Ziegler, U. Littmark, The Stopping and Range of Ions in Solids, Pergamon Press, New York (1985).

[21] H.H. Andersen, Appl. Phys., 18 (1979) 131-140.

[22] Z.C. Li, D.P. Yu, B.X. Liu, Phys Rev B, 65 (2002).

[23] Z.J. Zhang, O. Jin, B.X. Liu, Phys Rev B, 51 (1995) 8076-8085.

[24] P. Sigmund, Appl Phys Lett, 25 (1974) 169-171.

[25] S. Swaminarayan, M. Nastasi, Nucl Instrum Meth B, 267 (2009) 1713-1716.

\section{Figure Captions}

Figure 1. (a) Schematic illustration of in-situ irradiation. The depth profile of radiation damage on (b) Fe layers and (c) SiOC layers which is simulated by TRIM (a fluence of $4 \times 10^{14}$ ions $/ \mathrm{cm}^{2}$ ). Figure 2. The typical cross-sectional bright-field TEM micrographs of thin Fe/SiOC multilayer films (a) before, and after (b) $50 \mathrm{~K}$, (c) RT, (d) $573 \mathrm{~K}$ irradiation. The inset is the corresponding SAD pattern of each micrograph.

Figure 3. (a) The typical cross-sectional bright-field TEM micrographs of as-deposited thick $\mathrm{Fe} / \mathrm{SiOC}$ multilayer films. The microstructure evolution of films and after $50 \mathrm{~K}$ irradiation with a dose of (b) $4 \times 10^{14}$ ions $/ \mathrm{cm}^{2}$, (c) $1 \times 10^{15}$ ions $/ \mathrm{cm}^{2}$. (d) The scanning transmission electron microscope (STEM) images of thick Fe/SiOC multilayer films after $50 \mathrm{~K}$ irradiation with a dose of $1 \times 10^{15}$ ions $/ \mathrm{cm}^{2}$. The cross-sectional bright-field TEM images of thick Fe/SiOC multilayer films after (e) RT, (f) $573 \mathrm{~K}$ irradiation (a dose of $1 \times 10^{15}$ ions $/ \mathrm{cm}^{2}$ ).

Figure 4. (a) The simulated 3-D vacancy distribution inside the Fe layers. (b) The vacancy profile of Fe layer at the depth of $50 \mathrm{~nm}$. The data is fitted by Gaussian equation shown as red line. 
(a)
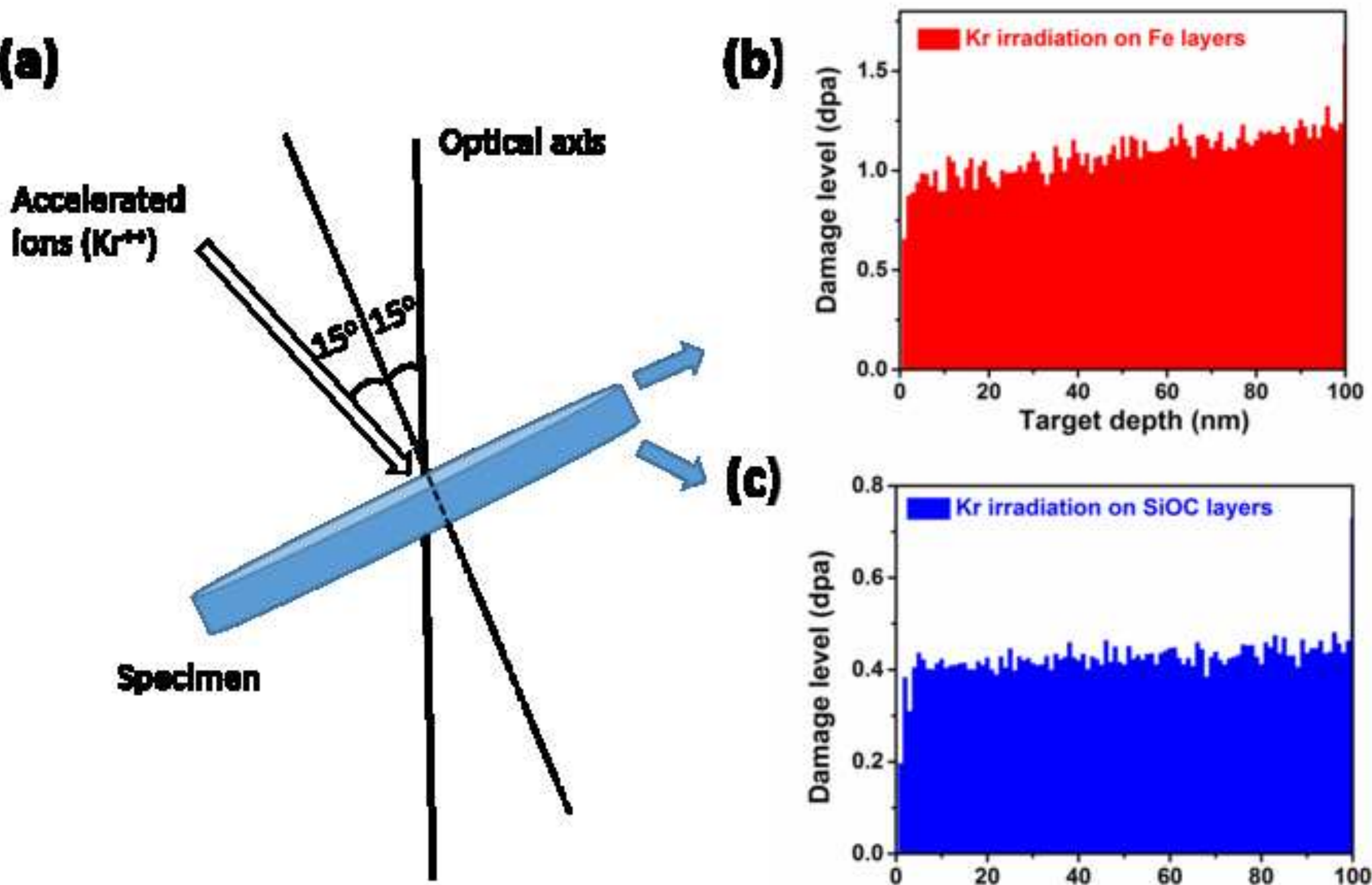

(c)

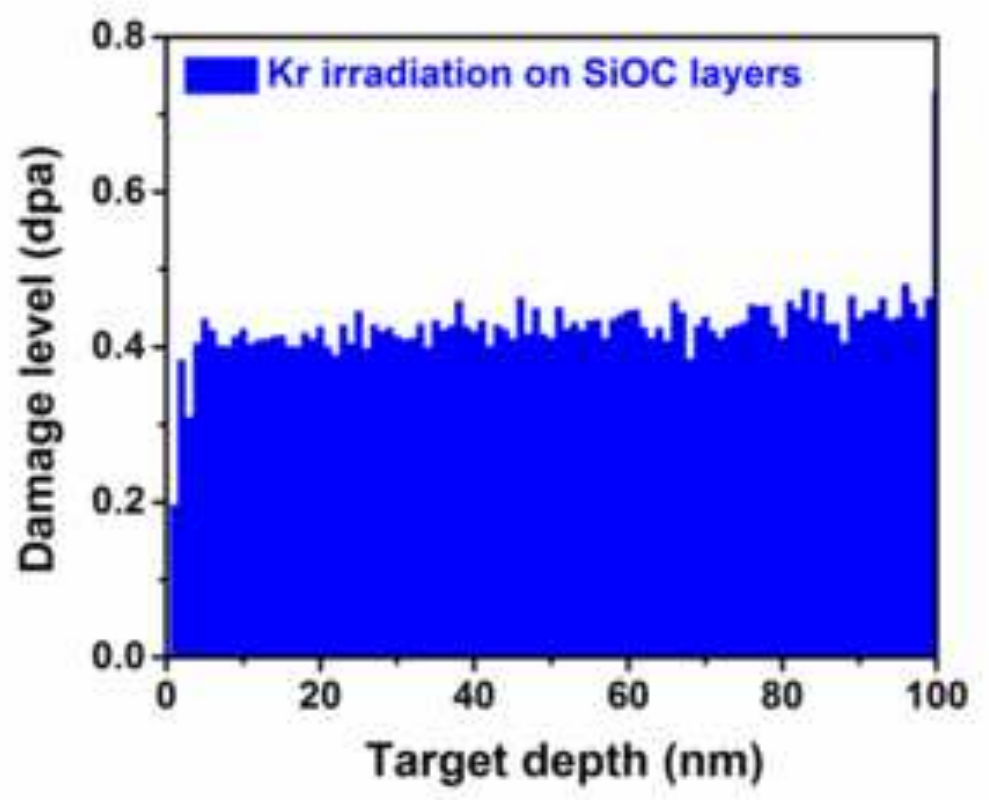


(a) Virgin

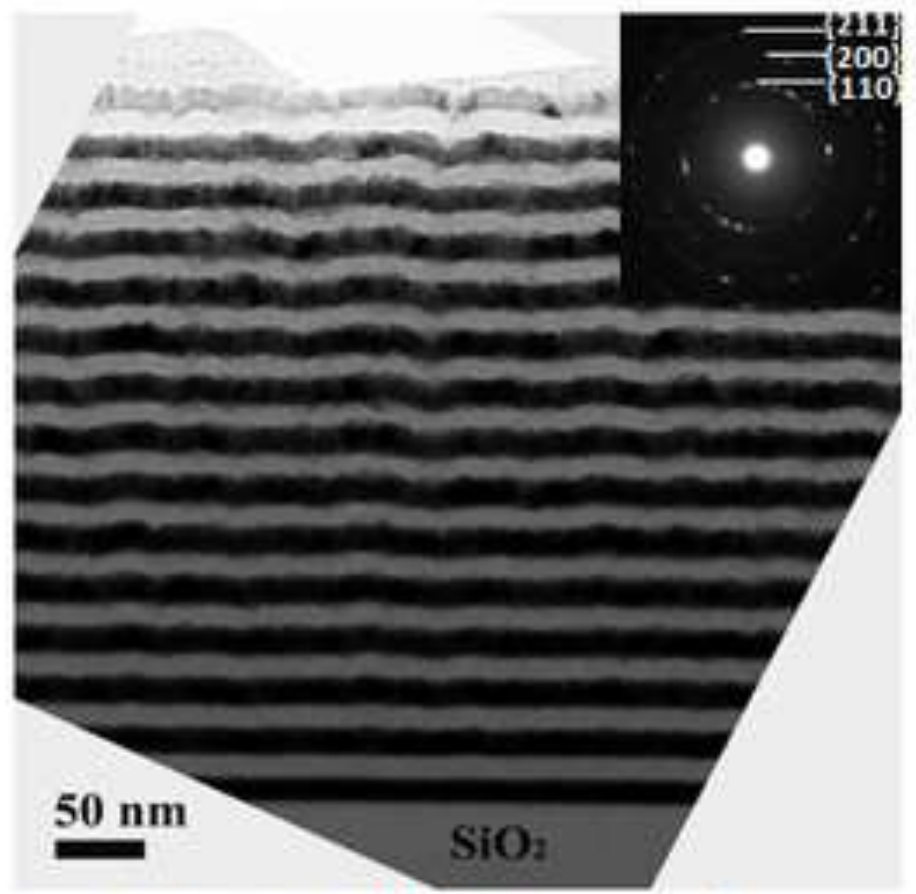

(c) RT, $4 \times 10^{14}$ ions $/ \mathrm{cm}^{2}$

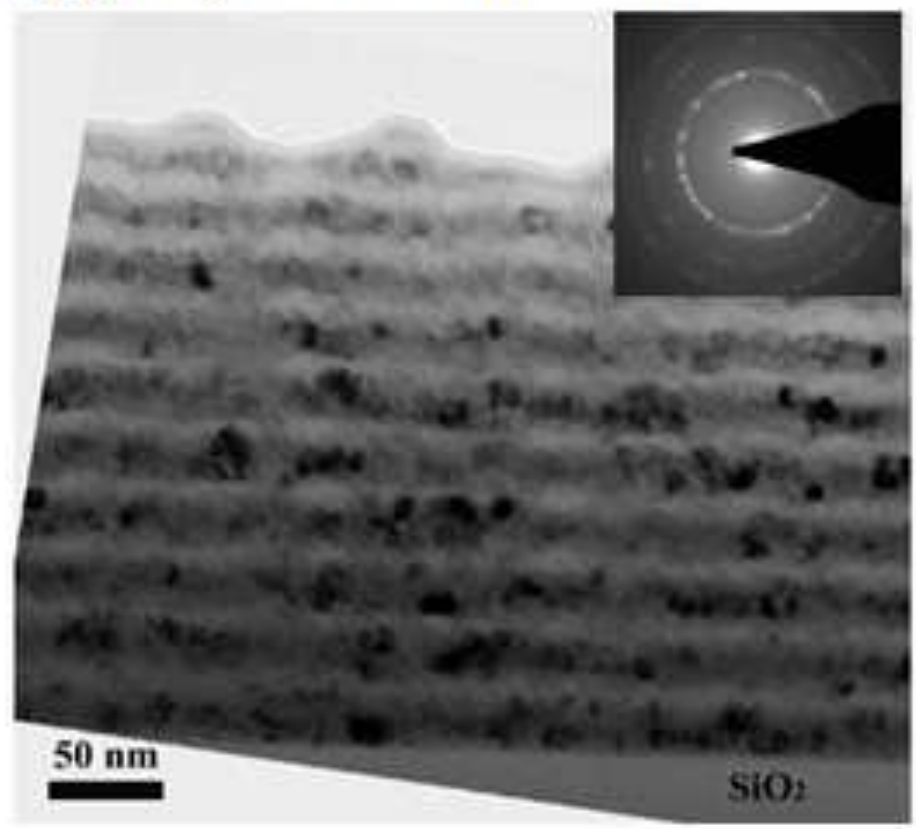

(b) $50 \mathrm{~K}, 4 \times 10^{14}$ ions $/ \mathrm{cm}^{2}$

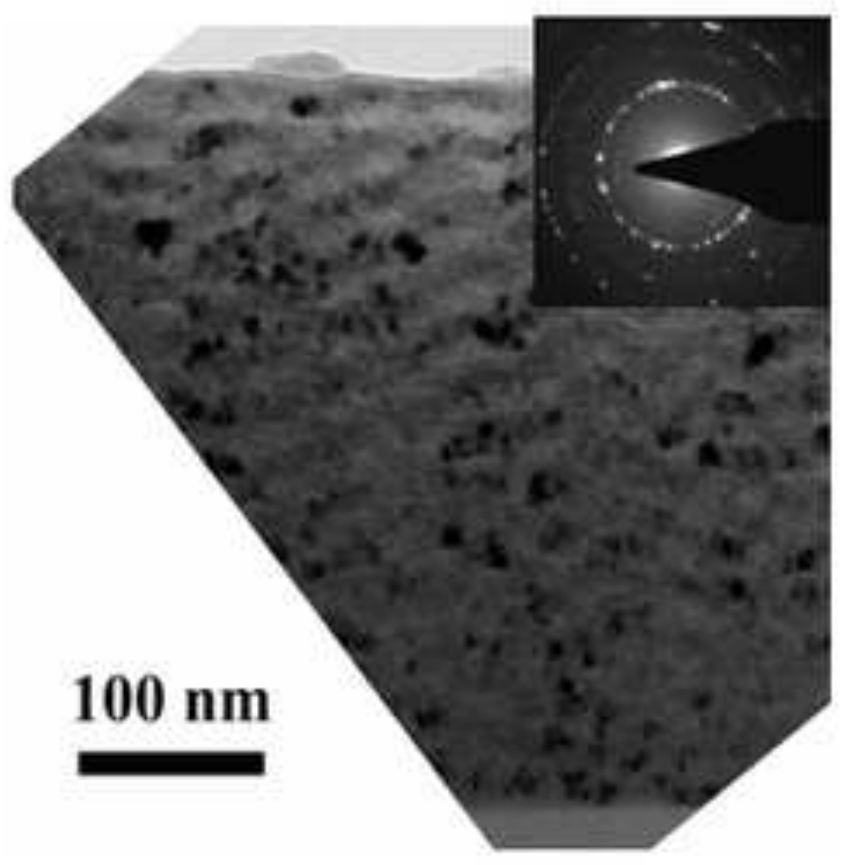

(d) $573 \mathrm{~K}, 8 \times 10^{14}$ ions $/ \mathrm{cm}^{2}$

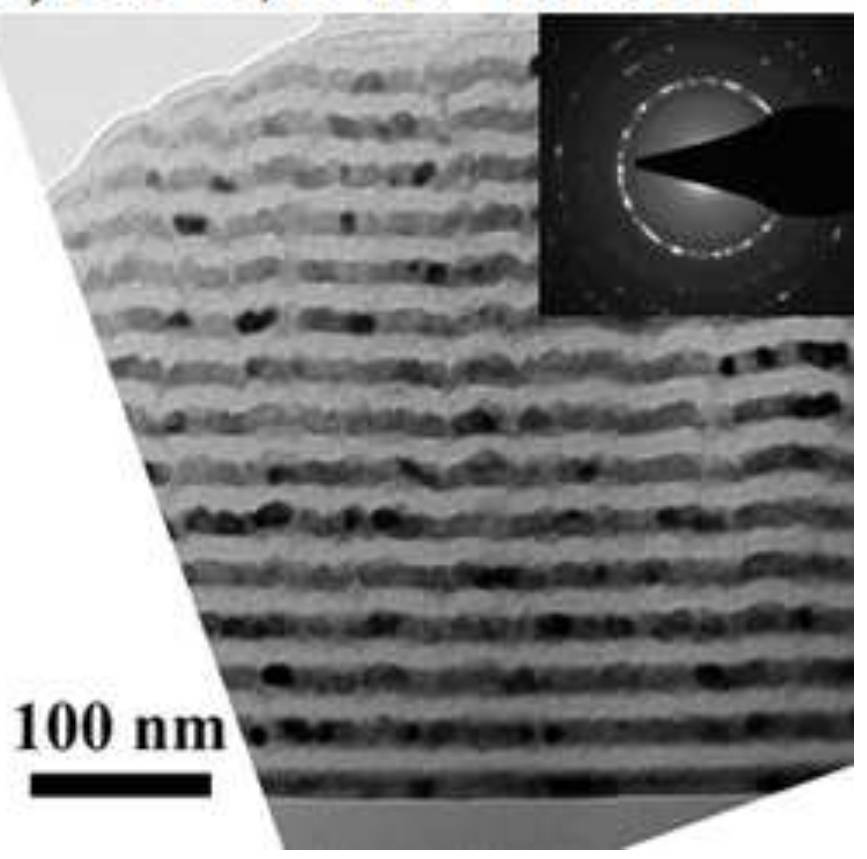


(a) Vridn

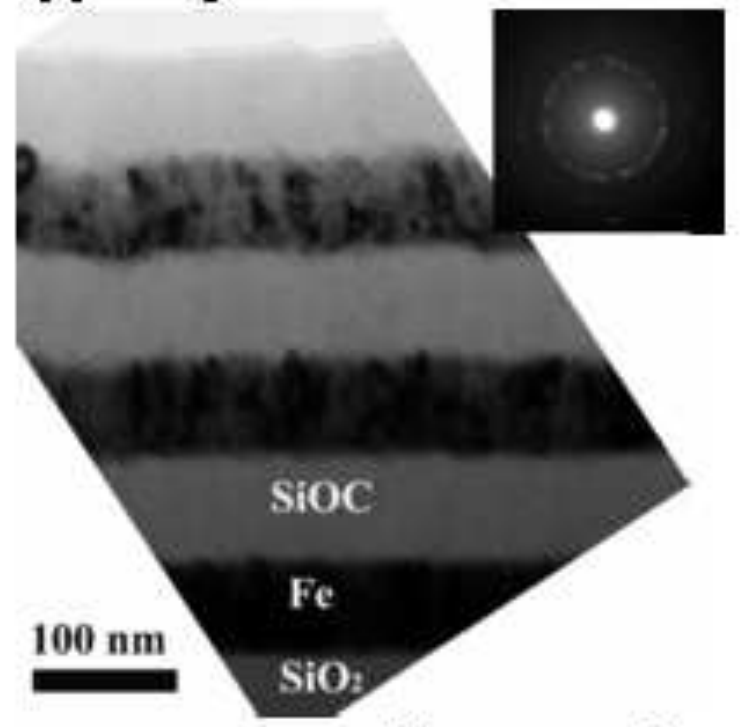

(c) $50 \mathrm{~K}, 1 \times 10^{16} \mathrm{lonag} / \mathrm{c}^{2}$

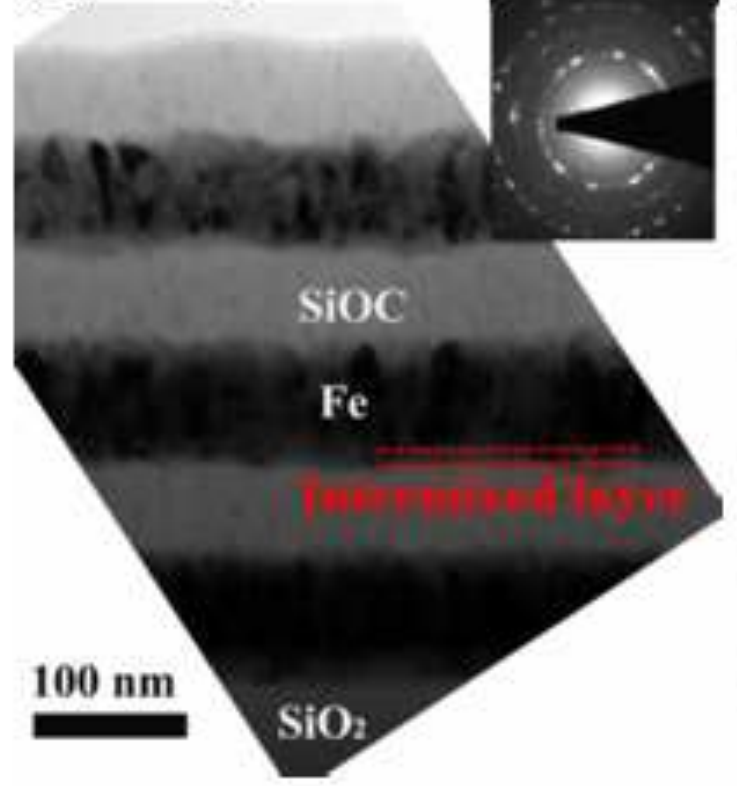

\section{(e) $\mathrm{KT}, 1 \times 10^{15} \mathrm{lnan} / \mathrm{com}^{2}$}

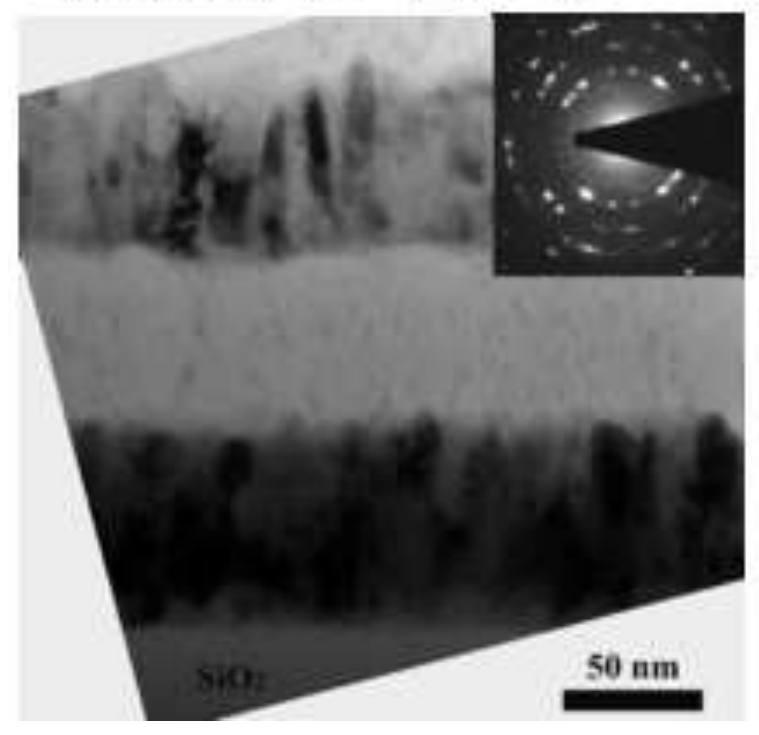

(b) $50 \mathrm{~K}, 4 \times 10^{14} \mathrm{inna} / \mathrm{cm}^{2}$

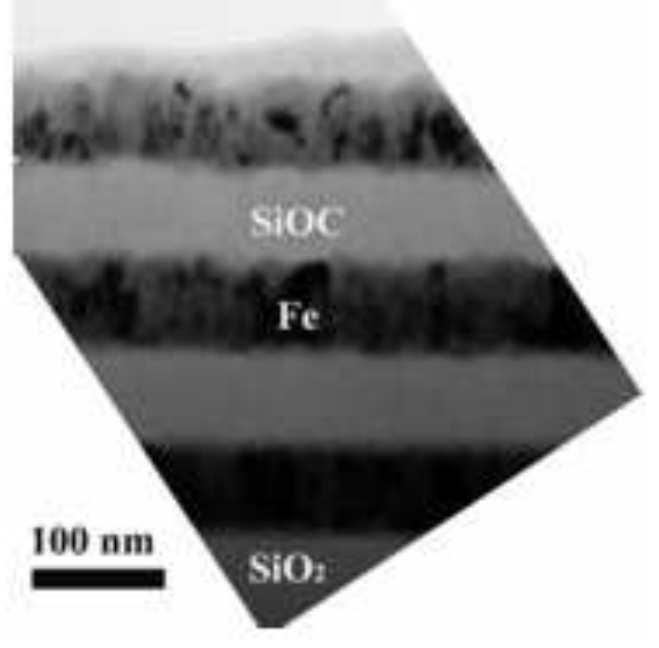

(d) $50 \mathrm{~K}, 1 \times 10^{13} \mathrm{man} / \mathrm{cm}^{2}$

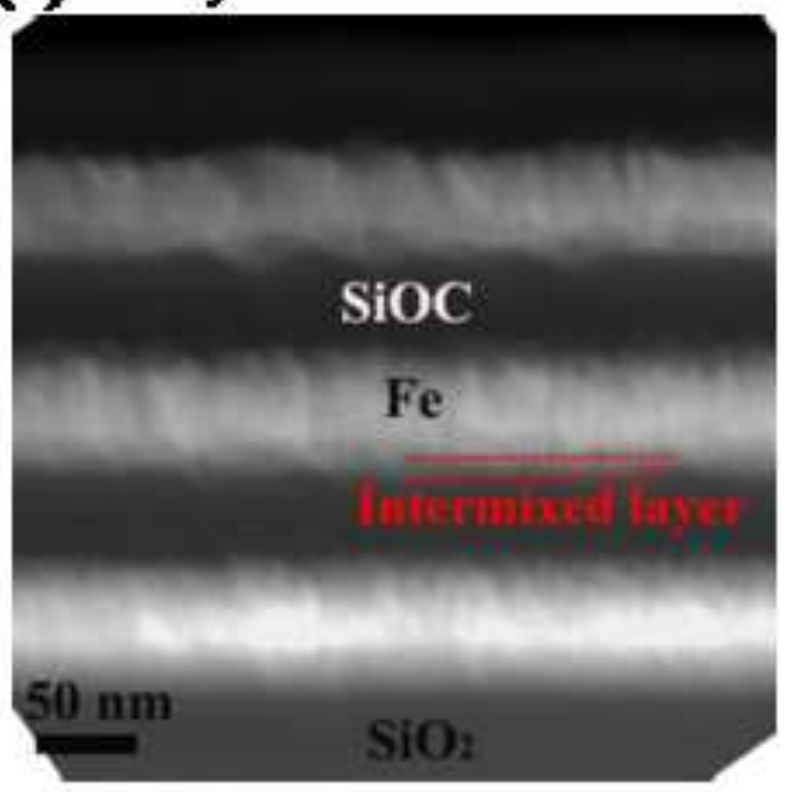

(f) $573 \mathrm{~K}, 1 \times 10^{15} \mathrm{lone} / \mathrm{em}^{2}$

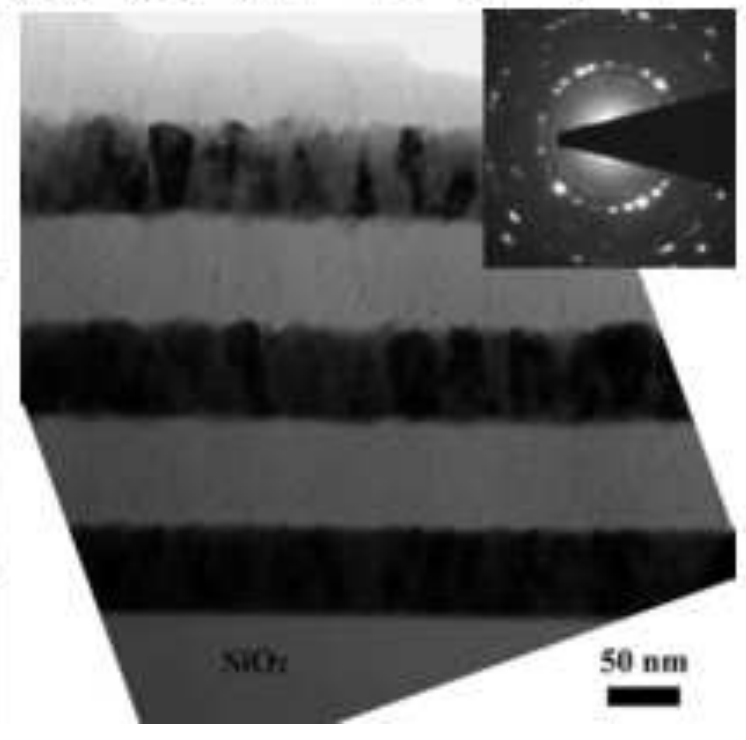


(a)

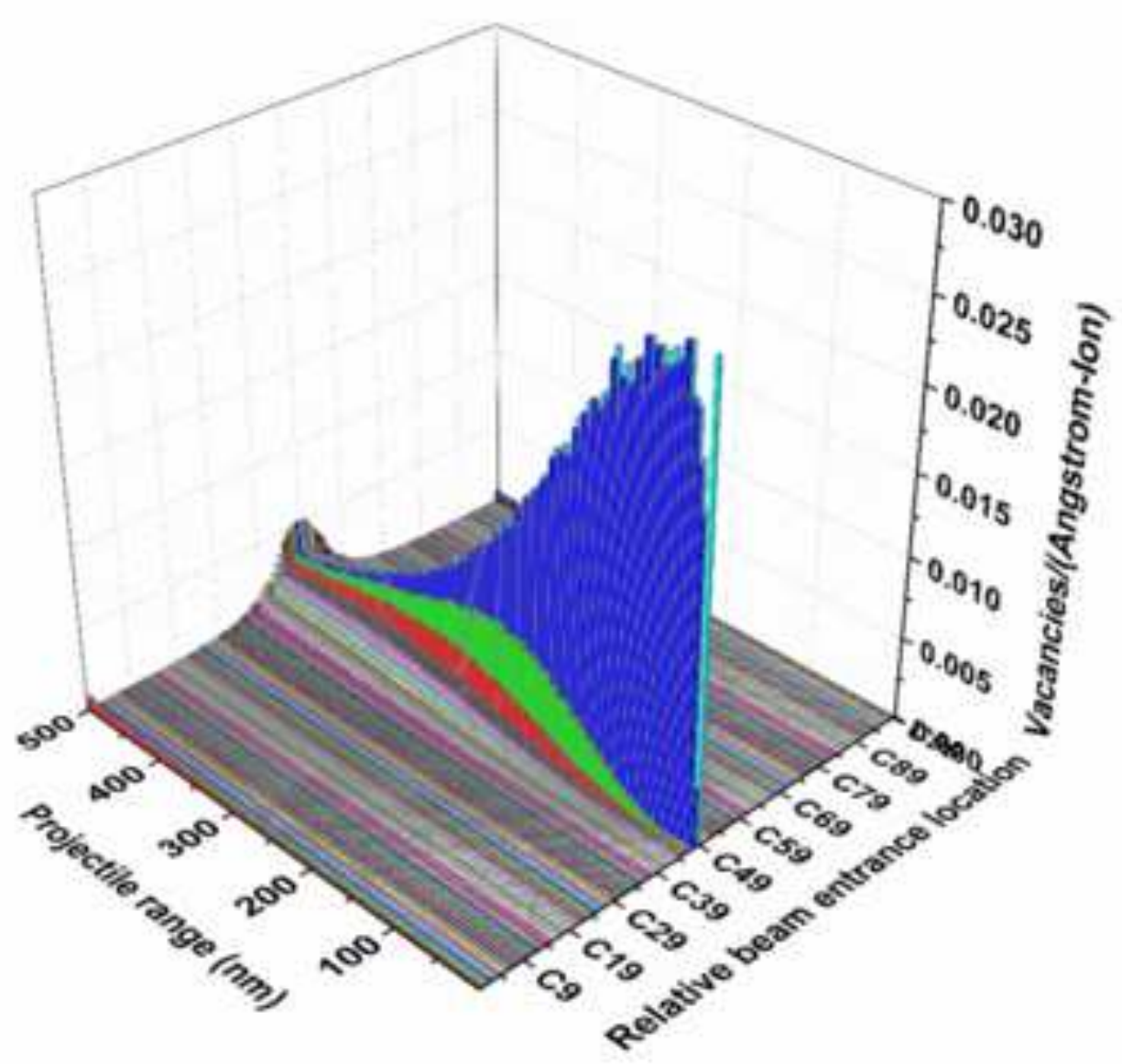

(b)

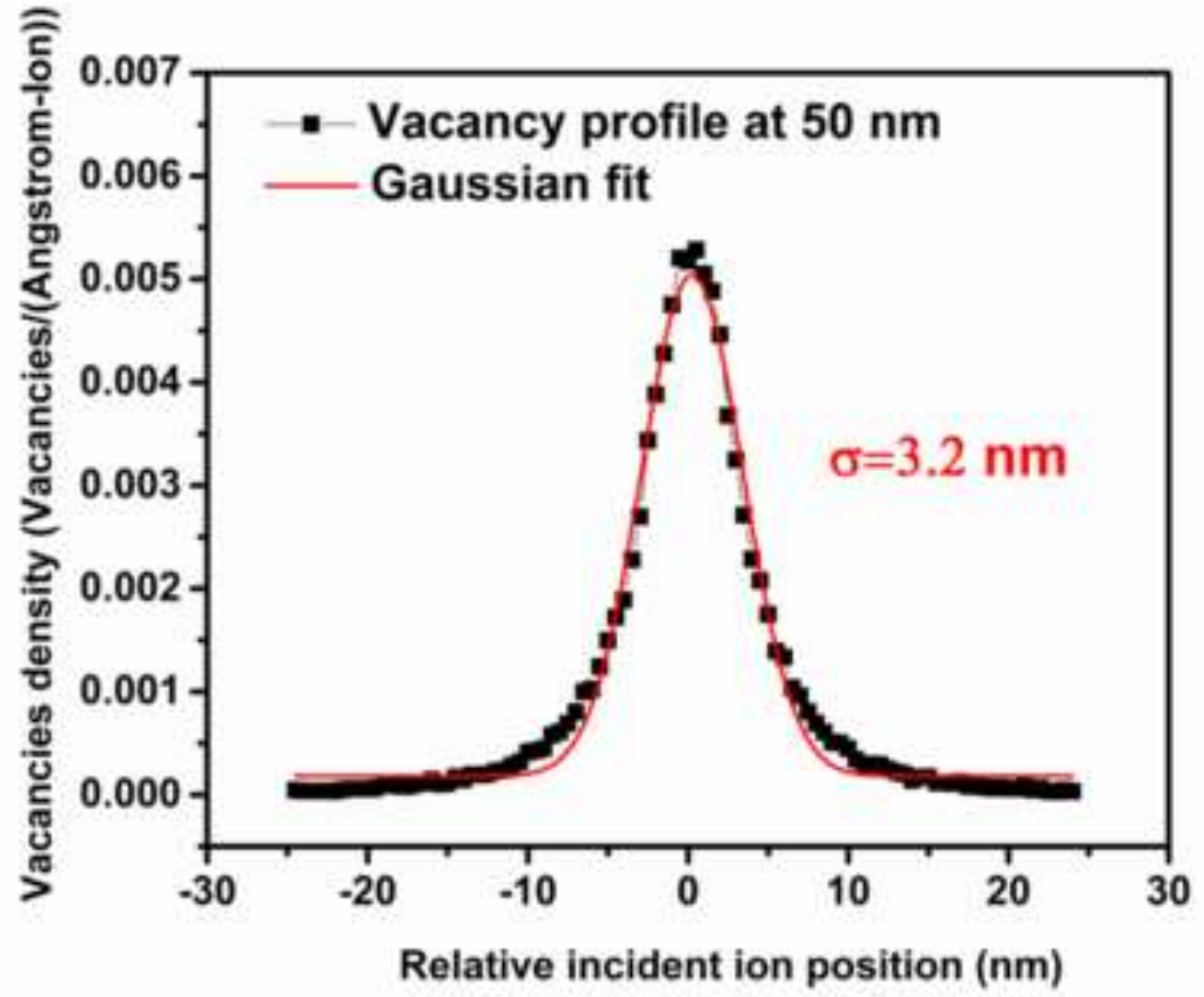




\section{Graphical abstract}

\section{In-situ Observation of Radiation Damage in Nano-structured Amorphous SiOC/Crystalline Fe Composite}

Qing Su, Bai Cui,Marquis A. Kirkand Michael Nastasi

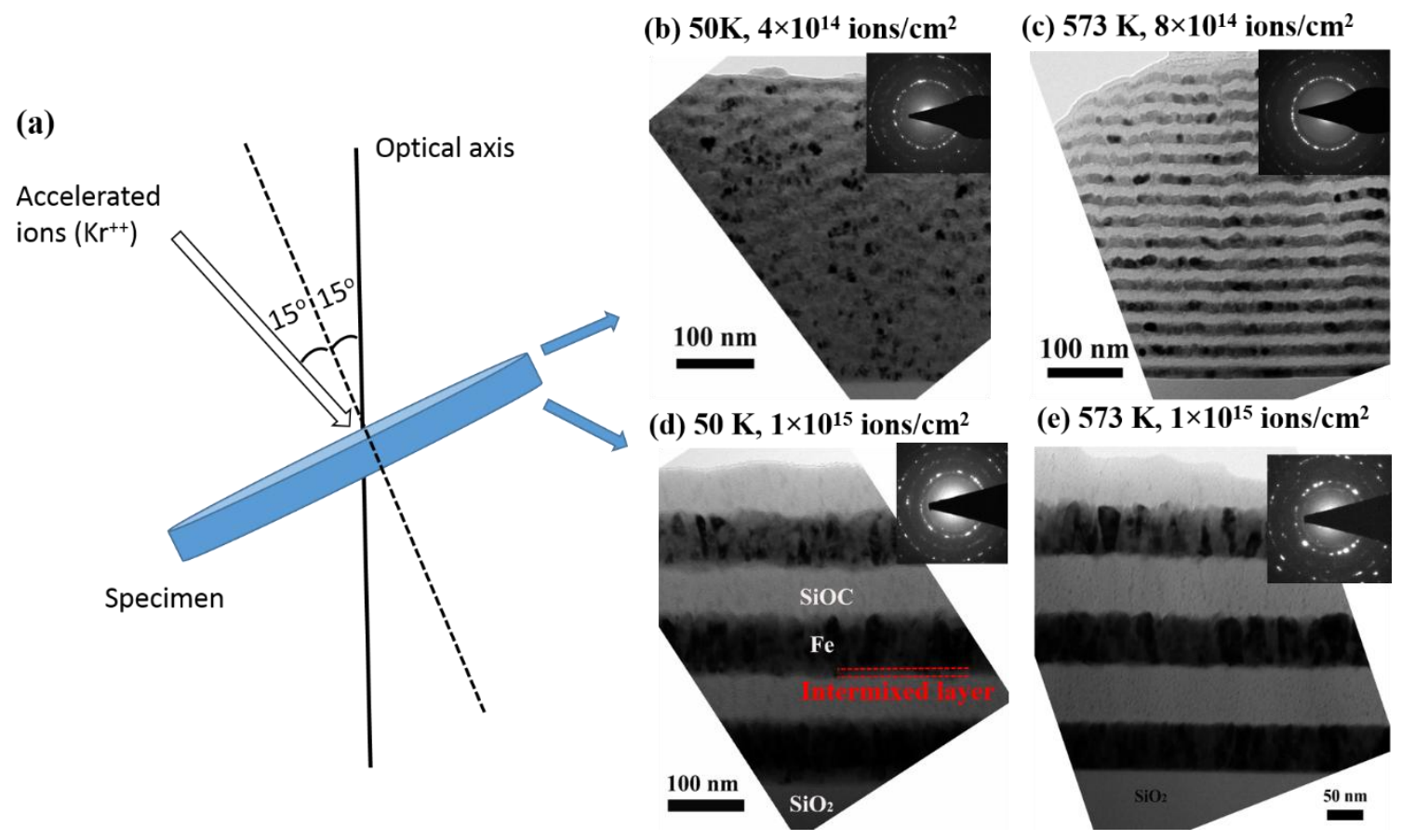

Fig. 1. (a) Schematic illustration of in-situ irradiation. The typical cross-sectional brightfield TEM micrographs of thin Fe/SiOC multilayer films after (b) $50 \mathrm{~K}$ and (c) $573 \mathrm{~K}$ irradiation with a dose of $1 \times 10^{15}$ ions $/ \mathrm{cm}^{2}$.Results clearly show that intermixing between $\mathrm{Fe}$ and $\mathrm{SiOC}$ is most severe for irradiationat $50 \mathrm{~K}$ and a demixing process is observedfor thin multilayer sample after irradiations at $573 \mathrm{~K}$. The cross-sectional bright-field TEM images of thick Fe/SiOC multilayer films after (e) $50 \mathrm{~K}$, (f) $573 \mathrm{~K}$ irradiation (a dose of $1 \times 10^{15}$ ions $/ \mathrm{cm}^{2}$ ). The results show a formation of intermixed layer after $50 \mathrm{~K}$ irradiation but no observed change after $573 \mathrm{~K}$ irradiation in thick Fe/SiOC multilayer sample. 